\title{
A novel control method for dispersed converters providing dynamic frequency response
}

\author{
Til Kristian Vrana · Christian Hille
}

Received: 30 August 2010 / Accepted: 10 May 2011 / Published online: 24 May 2011

(C) The Author(s) 2011. This article is published with open access at Springerlink.com

\begin{abstract}
Active power converters are flexible and highly dynamic. Many power converters, as battery charging devices, use only a small part of their technical capabilities. This paper develops a new control method that combines the primary converter function with grid frequency control. Doing this, the frequency stability can be influenced positively, using the power converters control potential, without penetrating its primary functions under normal power system conditions. In case of severe frequency deviations, priority is given to this grid support functionality, which can significantly improve the security of supply. If the converter's control algorithm does not take frequency stability aspects into consideration, the impact of thousands of these devices on the grid frequency stability will be negative. Electric and hybrid cars with battery storage and plug-in capabilities are used as an example for power conversion units. The impact of many cars, with the referred control method, on the UCTE (Union for the Co-ordination of Transmission of Electricity) grid frequency can be observed by simulations. Even a small percentage of electric cars can significantly influence the grid frequency after a power plant disconnection fault. No communication between network operator and converter is necessary for the basic grid supporting functions. Dispersed frequency support as suggested by the developed control method could be adopted as a requirement to future grid codes.
\end{abstract}

T. K. Vrana $(\bowtie)$

Norwegian University of Science and Technology,

Trondheim 7491, Norway

e-mail: vrana@ntnu.no

T. K. Vrana $\cdot$ C. Hille

RWTH-Aachen University, 52056 Aachen, Germany

C. Hille

e-mail: hille@ifht.rwth-aachen.de
Keywords Battery chargers - Control algorithm . Frequency control · Frequency stability .

Road vehicle power systems

\section{Introduction}

Frequency stability in AC grids is important for the entire system, since electrical motors and generators can be damaged, if operated at an inappropriate frequency. As a reliable power quality is a main advantage of high-wage industrial countries, frequency deviations pose the risk of severe economic impacts.

Under normal operating conditions, the frequency is held within a narrow margin by the primary control, the rotating inertia of generators and motors and by the fact that the power consumption of motors depends on the frequency.

The primary control on the one hand is mainly provided by large thermal power generation units and can directly be influenced via the controllers of those power stations. The rotating inertia and the frequency dependency on the other hand are based on the physical properties of all electrical generators and motors connected to the grid. These important stability mechanisms cannot be influenced directly.

The number of loads and generation units, connected via power converters, is steadily increasing. Therefore, the number of classical electrical motors and generators will decrease, since they are partly replaced by modern converterbased systems. The transition from synchronous generators used in thermal power stations, to induction generators, often used in wind turbines, causes similar problems. This development will bring up new challenges regarding frequency stability.

The serious incidents affecting the UCTE-grid in 2003 [1] and 2006 [2] have shown that critical system conditions 
are worsened by converter systems with improperly designed control units. It is possible though, to design converter system controllers in a way to avoid these problems [3].

Different concepts were proposed, how dispersed generation units could take part in frequency support. Hughes et al. [4] proposes a controller for doubly fed induction generator based wind turbines, that can supply additional power drawn from the energy that is mechanically stored in the rotor. The impact of wind turbines and a possible frequency support functionality is discussed in Lalor et al. [5] regarding the Irish power system.

In Dynamic Demand [6], a refrigerator is dynamically controlled depending on the frequency to support frequency stability. This load is not converter-based and therefore not suitable for the developed control method, but the case indicates how flexible loads can take part in frequency control.

The feasibility of droop control in low voltage grids has been investigated in Engler and de Brabandere [7,8], though focusing on local phenomena like harmonics, short circuits, and synchronism to the grid frequency. Stabilization of the grid frequency via droop control based on a flywheel energy storage system with converter interface is described in Hamsic et al. [9].

Modern converter systems are highly dynamic. Most of the converter systems do not utilize all of their technical possibilities to fulfil their primary task. Battery charging devices create not more than a DC current and can therefore take other tasks at the same time. Electrical vehicles with large batteries and plug-in capability are a good example for converter systems, which could support frequency control. Technical aspects of plug-in vehicles and vehicle-to-grid capabilities have been addressed in literature like Kramer et al. [10]. The grid supporting capabilities of grid connected electric vehicles are especially important for micro grids [11], which lack regular primary and secondary control. Plug-in vehicles are used as an example in this study, but there are several other converter systems that are suitable for the developed control method.

It is possible to imitate the behaviour of an electrical generator or motor with a power converter, by implementing a suitable control algorithm. Power converter systems with a control emulating the behaviour of a real synchronous machine are called virtual synchronous machines [12]. These virtual synchronous machines can operate both as a motor or generator.

Compared with other conventional loads, synchronous motors show an advantageous behaviour regarding frequency stability. The advantage of virtual synchronous machines towards real electrical machines is that physical properties such as the momentum of inertia can be chosen freely and changed easily, by adapting the relevant parameters of the control algorithm. The parameter values can exceed the range which is feasible for actual electrical machines and it is possible not only to imitate real machines, but also to achieve more beneficial properties than those found in conventional loads.

Under extreme emergency conditions, when the reserve power mechanisms are not capable of balancing the production and consumption, shedding of loads or generation units is the last option to keep the grid frequency within admissible boundaries. Non-priority converters can shed themselves in order to prevent more important systems from being shed. Continuous shedding comprises advantages as compared to classical stepwise shedding. This approach can be highly beneficial in case of the unlikely event of a severe system disturbance, but it has not been sufficiently addressed up to now.

Owing to an increasing share of volatile generation units, the demand for power reserves might double until 2040 [13]. If classical electrical generators and motors are not replaced by converter systems with a standard control, but with frequency supporting controllers, the frequency stability can benefit significantly from this change. The aim of the developed control algorithm is to be simple and general, so it can be adapted to future grid codes. No communication between network operator and vehicle is necessary for the basic grid supporting functions. More sophisticated vehicleto-grid applications like the ones described in Kempton and Tomic [14] and Guille and Gross [15] are compatible with this control method.

\section{The UCTE frequency model}

To be able to evaluate the effect of the developed control method on the grid frequency stability a Simulink model of the continental part of the grid controlled by the European Network of Transmission System Operators for Electricity (ENTSO-E) called UCTE-grid (Fig. 1) has been devised. The model simplifies the grid as it neglects its spatial extent. For the purposes of this paper, it is assumed that the frequency is the same at any point of the grid. For the implementation of load shedding, a fuzzy logic approach was used to compensate for the error created by this assumption.

This UCTE frequency model is simplified, yet accurate enough to calculate the effect of power imbalances on the grid frequency. The model takes into consideration:

- system inertia

- primary control

- frequency dependency of load

- load shedding

- pump storage power plants

Secondary control is neglected, since it has little influence on the system for the first few seconds in whom the fault occurs. 
Fig. 1 The UCTE frequency model

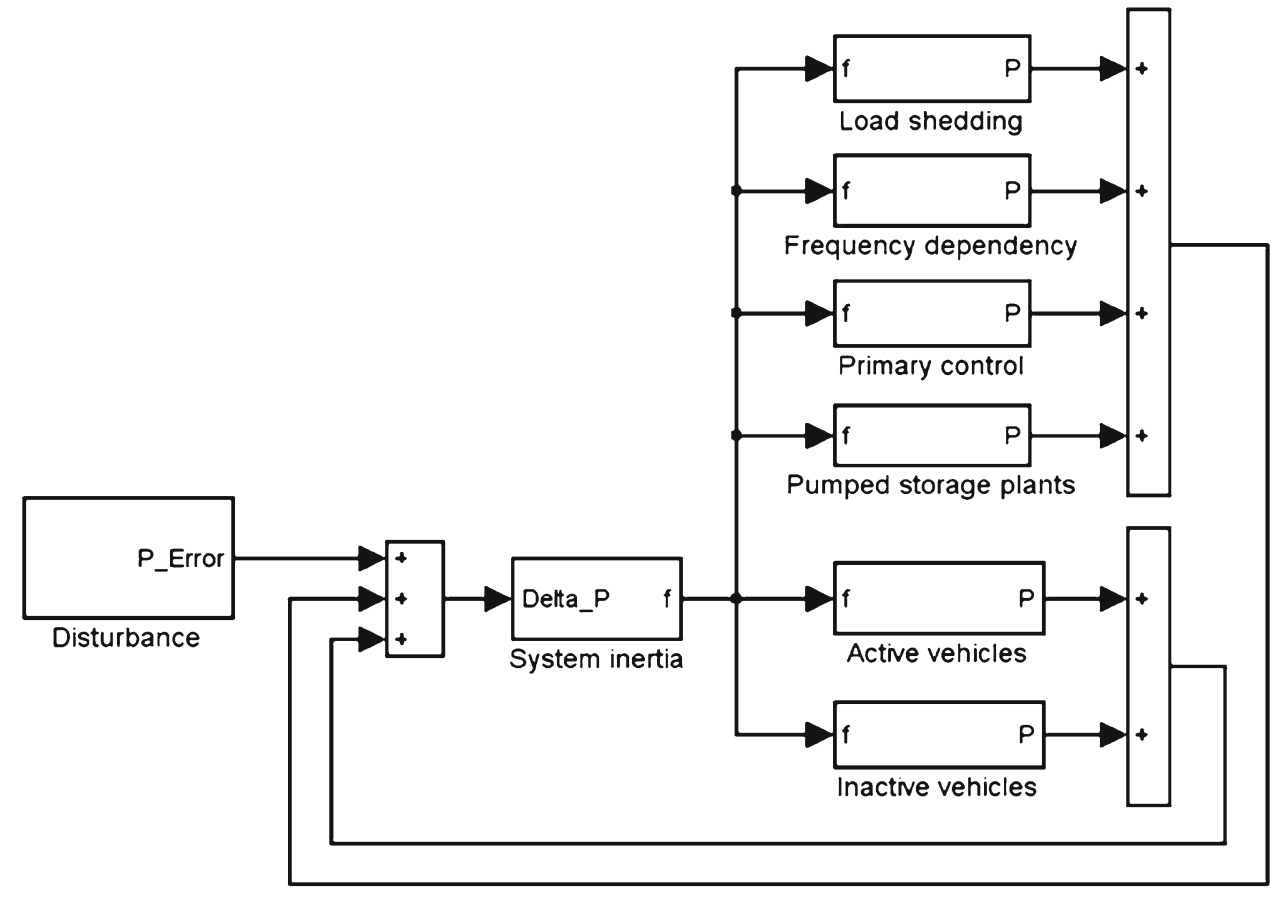

Reactive power is also neglected, since it does not directly influence the grid frequency. The system modelling is mostly based on Haubrich and UCTE [16, 17].

The model approximates the actual system behaviour, like it is today in Europe. Two simulations are run simultaneously, while one represents the grid control as it is today, and one which also comprises converter systems, controlled with the developed method.

These converter systems are represented by an active and an inactive electric car fleet:

- Active: The vehicle is connected to the grid and either loading the battery or supplying power to the grid.

- Inactive: The vehicle is connected to the grid but no energy is being transferred (battery has been charged to demanded level).

Electric vehicles can either receive energy or feed energy back into the grid. To make use of this capability, the state of charge of the batteries must at any time be neither completely full nor empty.

The two simulations make it possible to observe and evaluate the effect of additional dispersed converter-based frequency control. The developed control method is in principle suitable for most kinds of converter systems, but is exemplified by electric cars.

The model was used to simulate several kinds of system disturbances considering different quantities of vehicles. The simulations presented within this paper will however focus on a reconstruction of the fatal incident in November 2006, when the UCTE-grid was split into three zones [2]. The two critical zones (Western Europe and North-Eastern Europe) were simulated and the results are presented in Sect. 5.

\section{Mathematical equations of a synchronous motor}

To develop a control algorithm based on a virtual synchronous motor, the power-frequency behaviour of the real synchronous motor has to be analyzed mathematically. It is sufficient for the development of a control algorithm to assume a machine with one pair of poles for each phase. Transient phenomena are ignored, so angular velocity of the grid voltages and the machine are equal at all times. All equations are linearised at the operation point $\omega_{0}$ for the nominal angular velocity.

First the normalized angular velocity deviation is defined:

$\omega^{\prime}=\frac{\omega-\omega_{0}}{\omega_{0}}$

The dependency of the torque on the angular velocity in steady state can be approximated with a Fourier sequence. Since the deviations of the angular velocity in electric grids are very small ( $0.4 \%$ under normal conditions) a linear approximation is sufficient. The quadratic term and all following can be neglected. The torque of a synchronous motor, which consists of a steady state and a dynamic part, can be written:

$M(\omega)=M_{0} \cdot\left(1+K_{\mathrm{M}} \cdot \omega^{\prime}\right)+L_{0} \frac{\mathrm{d} \omega^{\prime}}{\mathrm{dt}}$ 
The parameter $K_{\mathrm{M}}$ represents the dependency of the torque on the angular velocity. $L_{0}$ is the angular momentum at $\omega_{0}$. Now, the frequency dependency of the power consumption is calculated, since this is relevant for the power frequency control. The standard equation for mechanical power in rotating systems is

$P=M \cdot \omega$

(2) inserted into the power equation (3) results in:

$P=M_{0} \cdot\left(1+K_{\mathrm{M}} \cdot \omega^{\prime}\right) \cdot \omega+L_{0} \cdot \omega \cdot \frac{\mathrm{d} \omega^{\prime}}{\mathrm{d} t}$

The angular velocity can be expressed via the normalized angular velocity deviation:

$\omega=\omega_{0} \cdot\left(1+\omega^{\prime}\right)$

(5) inserted into (4) leads to

$P=M_{0}\left(1+K_{\mathrm{M}} \cdot \omega^{\prime}\right) \omega_{0}\left(1+\omega^{\prime}\right)+L_{0} \omega_{0}\left(1+\omega^{\prime}\right) \frac{\mathrm{d} \omega^{\prime}}{\mathrm{d} t}$

Now the following approximations are introduced:

$\omega^{\prime 2} \approx 0$

$1+\omega^{\prime} \approx 1$

Using (7) and (8), (6) can be rewritten as:

$P=M_{0} \omega_{0}\left(1+\left(1+K_{\mathrm{M}}\right) \cdot \omega^{\prime}\right)+L_{0} \omega_{0} \frac{\mathrm{d} \omega^{\prime}}{\mathrm{d} t}$

The nominal power is introduced

$P_{0}=M_{0} \cdot \omega_{0}$

This leads to

$P=P_{0}+P_{0} \cdot\left(1+K_{\mathrm{M}}\right) \cdot \omega^{\prime}+P_{0} \frac{L_{0} \omega_{0}}{P_{0}} \frac{\mathrm{d} \omega^{\prime}}{\mathrm{d} t}$

Similar to the angular velocity, the normalized power deviation can be defined

$P^{\prime}=\frac{P-P_{0}}{P_{0}}$

(11) can be written as

$P^{\prime}=\left(1+K_{\mathrm{M}}\right) \cdot \omega^{\prime}+\frac{L_{0} \omega_{0}}{P_{0}} \frac{\mathrm{d} \omega^{\prime}}{\mathrm{d} t}$

Now two new parameters are introduced:

$K_{\mathrm{P}}=1+K_{\mathrm{M}}$

$T_{\mathrm{A}}=\frac{L_{0} \cdot \omega_{0}}{P_{0} \cdot K_{\mathrm{P}}}$
This leads to:

$P^{\prime}=K_{\mathrm{P}}\left(\omega^{\prime}+T_{A} \frac{\mathrm{d} \omega^{\prime}}{\mathrm{d} t}\right)$

Equation (16) demonstrates that the synchronous motor shows the behaviour of an ideal PD controller. In Sect. 4, a control method for power converters is developed, which is based on this behaviour.

\section{The control strategy}

In this section, the active power control strategy of the converters is presented. The reactive power of the converter is set to zero as demanded by actual grid codes [18], which should be subject to further investigation. The structure of the control is shown in Fig. 2.

Every converter is operated at a specific value for the demanded power. For the short time frame addressed here, this demanded power can be seen as constant. On a longer time scale, it is of course not constant, but depends on the battery charging strategy. Possible vehicle-2-grid application like providing secondary frequency control power from electric vehicles can be combined with the developed control strategy. This promising future option is however beyond the scope of this article, which focuses on autonomous and automatic basic grid support. The developed control method is designed to allow vehicle-to-grid applications in addition to the basic grid support via influencing the demanded power. It is important although that any changes in the demanded power happen rather slowly to avoid interaction with the faster inner control loops.

Based on the demanded power, the steady state power order is calculated, which is a function of the frequency. This represents the proportional part of the control. Based on the frequency gradient, the differential part of the control is calculated and added, to determine the ideal power. This ideal power is then low pass filtered, to avoid unwanted reactions towards frequency noise. The filtered ideal power is finally limited, if it exceeds the rated power of the converter.

The developed control strategy works for loads, sources and also bidirectional storage units. In this paper, the example of loading electric vehicles is chosen, which appear as loads. All further explanations will focus on converter systems operated as loads.

\subsection{Proportional part of the control}

Under normal grid operation conditions, the active power should behave like a virtual synchronous motor. For more critical system states, different strategies are used and described in the following. First the stationary power order of the converter depending on the grid frequency is explained: 
Fig. 2 The structure of the active power control

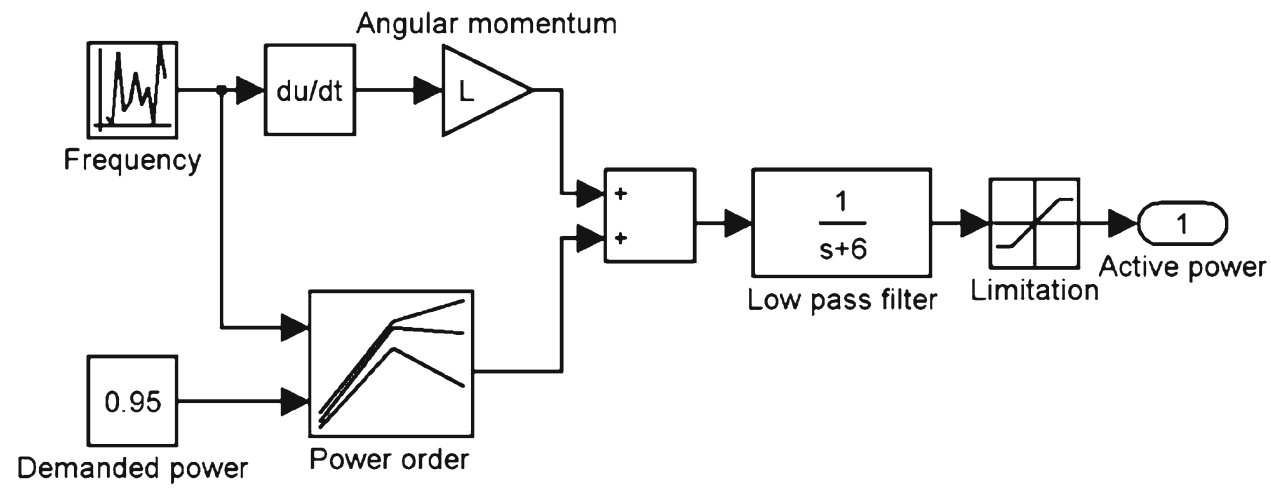

Seven important frequencies are given by the operational practices of the UCTE-grid [17]:

- $f 1=47.5 \mathrm{~Hz}$

- $f 2=49.0 \mathrm{~Hz}$

- $f 3=49.8 \mathrm{~Hz}$

- $f 4=50.0 \mathrm{~Hz}$

- $f 5=50.2 \mathrm{~Hz}$

- $f 6=51.0 \mathrm{~Hz}$

- $f 7=52.5 \mathrm{~Hz}$

$f 4$ is the standard grid frequency; $f 3$ and $f 5$ are the limits of normal operational conditions. If the grid frequency lies outside the margin of $200 \mathrm{mHz}$ above and beneath $f 4$, the system operates under major fault conditions. The boundaries for the major fault conditions band are $f 2=49.0$ and $f 6=51.0 \mathrm{~Hz}$. If that frequency band is abandoned, the system is in disaster conditions. The final borders of system operation are $f 1$ and $f 7$. If this frequency band is exceeded, the system will collapse.

The power order of the converter depending on the grid frequency is shown in Fig. 3. The different graphs show different demanded power values from maximal battery charging to zero power consumption. Each curve shows the frequency dependent power order of a converter with a specific value for the demanded power, while positive power order represents power consumption.

The upper curve shows a converter operated at the maximum demanded power of $95 \%$ of its rated power. The lowest curve shows the case of an inactive power converter, so the power order is zero under normal grid operating conditions.

Below $f 2$ and above $f 6$ all converters show the same behaviour, since their primary task is neglected in these cases. The details in Fig. 3 are described in the following subsections.

\subsubsection{Normal operation}

To achieve synchronous motor behaviour under normal system conditions, power consumption is supposed to rise

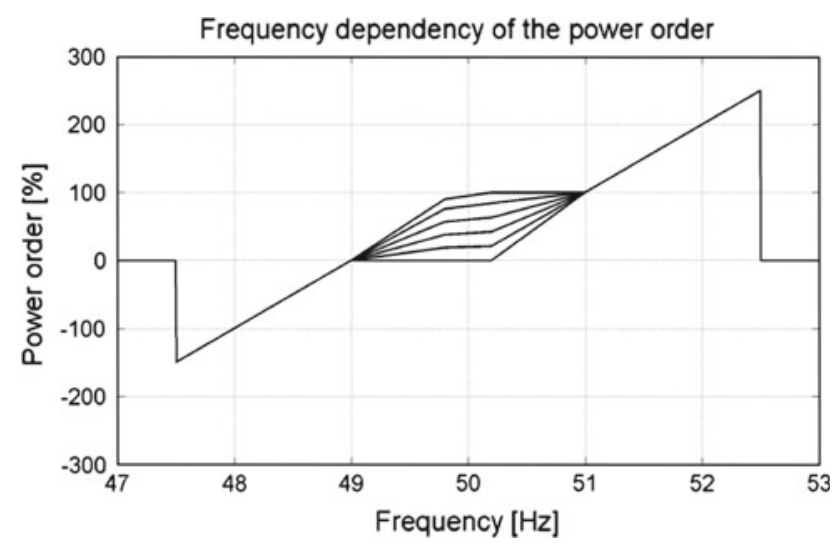

Fig. 3 The frequency dependency of the power order for loads

linearly between $f 3$ and $f 5$. The maximal demanded power has to be limited at $f 4$ to keep a margin to react towards rising frequency. The maximum value for the frequency dependency is determined by the size of that margin. A margin of $5 \%$ should be tolerable, so the demanded power of the converters is limited to $95 \%$ at $f 4$. If the power order of a converter operated at the limit should reach $100 \%$ at $f 5$, the frequency dependency is $26.3 \% / \mathrm{Hz}$. Regular loads only reach values up to $6 \% / \mathrm{Hz}$.

This margin should be feasible, since converters are usually not operated at their absolute limit. Owing to the short-term over-power capability of converters, it should be possible to implement this control without relevant draw backs. This of course will need to be verified, to make sure the frequency support task does not interfere with the primary task of the converter. If this assumption will be proven wrong, the margin and frequency dependency could be reduced. To achieve a frequency dependency of $6 \% / \mathrm{Hz}$, a margin of only $1.2 \%$ would be needed. The UCTE assumes the average frequency dependency to be only $1 \% / \mathrm{Hz}$ [17], which could be achieved with a margin of $0.2 \%$.

If the frequency dependency would be chosen zero, the converter could operate in the dead band between $f 3$ and $f 5$ without being under the influence of the grid frequency. Assuming a large part of the future load being 
converter-based, this is problematic. Within the dead band, the frequency would become more volatile due to the smaller share of load without a dead band.

If the required margin turns out to be problematic, the control method could also still be applied at times, when the converter operates at lower power than the absolute maximum. Battery loading strategies suggest that this will be the case for most part of the loading cycle.

The power variations have to be relative to the demanded power, not to rated power. Otherwise operation at low demanded power would be disturbed [18]. If the proportional part of the control would relate to the rated power, it could be in the same range as the demanded power (if that is at a low value). In this case, the control power would have significant influence on the primary task of the converter, which cannot be tolerated under normal operation conditions.

This leads to a converter operated at maximum capacity (95\% at $f 4$ ) reaching a power setting of $100 \%$ at $f 5$, while a converter utilizing half its capacity $(47.5 \%$ at $f 4)$ will reach a power setting of $50 \%$ at $f 5$.

\subsubsection{Major fault condition}

If the frequency falls below $f 3$, it is helpful to shed nonpriority loads to save more important loads. Converter systems like battery charging devices can measure the frequency and shed themselves autonomously. Therefore, all converter loads should decrease their power consumption to reach minimal consumption at $f 2$. If frequency rises above $f 5$ consumption should increase for all converters, reaching $100 \%$ at $f 6$. While a converter operated at the maximum capacity of $95 \%$ reaches $100 \%$ at $f 5$, all converters reach $100 \%$ at $f 6$ not depending on their demanded power setting.

Continuously shedding dispersed non-priority loads is an ideal system to handle large power imbalances. A PD controller without this feature would counteract frequency restoration after a massive frequency drop because it would try to stop the rising frequency (due to the differential part), disregarding the under frequency condition and such a problem occurred in de Haan and Visscher [19].

\subsubsection{Disaster control}

Below $f 2$ and above $f 6$ the entire power system is under disaster conditions. The primary task of the converters should therefore be neglected, and the control should switch to full grid support. The proportional part of the control should then exceed $100 \%$ to disable the differential part.

All converters have a power frequency relationship of $100 \% / \mathrm{Hz}$, not depending on the demanded power setting. At $f 1$ power consumption reaches $-150 \%$ and at $f 7$ power consumption reaches $250 \%$ as well. A differential part of more than $150 \%$ would be needed, to make a difference. Therefore, converters will still not consume power at $48.0 \mathrm{~Hz}$ even if the frequency is rising slowly.

\subsubsection{Collapsed grid}

The final borders of system operation are $f 1$ and $f 7$. If this frequency band is exceeded, the system will collapse. The collapse above $f 7$ will not happen in reality, since at that frequency generation units will disconnect from the grid, which will automatically restore the balance [16]. In these cases, the converters should as well be disconnected from the grid.

It is important although that if the collapsed grid is reactivated, converters do not switch on instantly. The black start of a collapsed grid is a difficult process. The converters should not interfere in the first seconds after a black start, but they should reconnect themselves slowly, and ramp up to their regular behaviour within minutes.

\subsection{Differential part of the control}

The differential part of the frequency control of a virtual synchronous machine is proportional to the angular momentum of the machine, which was chosen as a control parameter. Since the differential control part highly reacts towards high frequent noise, it is necessary to apply a low pass filter on the control, which was also identified in Lalor et al. [5].

The angular momentum should be as large as possible if it were not limited by the noise. A too large angular momentum would also have the disadvantage, that the reaction towards a fault would exceed the limitations of the power converter. This problem was identified in de Haan and Visscher [19].

The choice of the angular momentum highly depends on the low-pass noise filter chosen. If noise is reduced significantly by that filter, a larger angular momentum can be chosen, but the control will react slower due to that filter. The best compromise was found at an angular momentum of $4 \mathrm{~s}^{2}$ times the rated power of the converter (with a filter time constant of 6s). This compromise is based on the simulations with different fault types and noise levels.

This angular momentum is by far larger than the corresponding value of real electrical machines and relates to a start up time constant of about $10 \mathrm{~min}$. A real synchronous machine with such a large momentum would probably lose synchronism if the frequency changes, but this will not cause problems for virtual synchronous machines.

\subsection{Low-pass noise filter}

To reduce the reaction on the frequency noise, the control output needs to be filtered with a low pass filter. This filter should be a simple first-order low pass, to reduce oscillations when primary control and converter system trigger each other. Simulation results show that a filter time constant 
of $6 \mathrm{~s}$ is a good compromise, between control dynamics and noise resistance. Longer time constants are better suitable for reduced noise level, but the control will be slowed down. Since the main advantage of this dispersed converter-based control is the fact that it can react faster than the primary control, a large time constant of the filter is counterproductive.

In comparison with real electrical machines $6 \mathrm{~s}$ is a large time constant, which indicates that the robustness towards frequency noise of a virtual synchronous machine with the suggested control method would be rather good.

\subsection{Power and energy limitations}

The power (consumption or production) of the converter consists of the demanded power plus the filtered control power. The determined power value can exceed the power rating of the converter. Therefore a limitation is necessary, to protect the hardware from being overloaded. The same applies to storage systems that at some point are not capable of consuming or delivering power.

\subsection{Converter systems operating as sources}

If the control strategy is applied to power sources, the proportional part of the control has to be adapted, while the differential part and the low pass filter remain unchanged.

Converter systems, which are not operated as loads, but as generation units, also have to be frequency depended. The reaction towards frequency deviations has to be inverted, to support grid stability. If the frequency drops, consumption should decrease, while generation has to increase. This behaviour of the implemented control deviates from the behaviour of real synchronous generators.

The main part of the set of curves, which is in Fig. 3 between 100 and $0 \%$, is now placed between -100 and $0 \%$, since power consumption is considered positive. This will move the upper total boundary to $+150 \%$ and the lower total boundary to $-250 \%$. The equivalent set of curves can be found in Fig. 6 in the Appendix.

\subsection{Bidirectional converter systems}

Bidirectional converter systems with energy storage can support the power system with consumption and production. The main part of the set of curves from Fig. 3 is therefore between $-100 \%$ and $+100 \%$ in this case. The total boundaries are at $+250 \%$ and $-250 \%$. The equivalent set of curves can be found in Fig. 7 in the Appendix.

An inactive converter system (the middle curve) has a zero power order between $f 3$ and $f 5$. If the grid frequency drops below $f 3$ power is produced, and if grid frequency rises above $f 5$ power is consumed from the grid.
Bidirectional system offer the best grid support functionality and electric vehicles with battery would be perfectly suitable for this. However, the electrical distribution infrastructure was designed for unidirectional use, so a bidirectional power converter cannot be used without adaptations of the system. Smart substations or some other kind of control entity would be needed to guarantee that reversed power flows stay within permitted boundaries.

The recent developments in the smart grid field imply, that smart substation could be realized in the near future, to make bi-directional vehicle-to-grid (V2G) applications possible, which would also enable electric vehicles to connect as bidirectional systems, improving the grid support functions. This would also solve possible problems with conventional load shedding, since regions which supply power could be shed, if no flexible control is applied.

Owing to safety reasons, the connection type must instantly be switched to standard, if the communication between the converter system and the smart substation is lost; otherwise, a region that has been intentionally cut off could supply itself with dispersed generation and feeding converters.

Intelligent substations could also regulate the reactive power supply by the converter systems and support voltage stability.

\subsection{Active and inactive converters}

Converters connected to the grid can either be active or inactive. An active converter is either supplying or consuming power, while an inactive converter is operated at a preferred power rating of zero. An example for an inactive converter is an electric car, which is charged to the demanded level, and therefore not consuming any more power. The difference between an inactive converter and an active converter with a demanded power of zero is that for the inactive converter the differential part of the control is disabled.

Those inactive converters can supply a service in emergency situations, but they need to remain in standby and observe the grid frequency constantly, to detect these situations. If the grid frequency falls below $f 3$, inactive converters (generation and storage) can activate themselves and then behave like regular active converters with a desired power of zero. The same applies if the frequency rises above $f 5$ (storage and loads). If system conditions are stabilized and grid frequency comes back to the normal operation band, these activated converters can deactivate themselves again, but should do this slowly within minutes.

If smart substation are realized in the future, inactive converters should remain logged in, to allow a better overview over the available resources. 


\section{Simulation results}

To show the improvement of frequency stability using the developed control method, the incident in 2006 leading to a blackout situation in parts of the UCTE-grid and described in Maas et al. [2] is reconstructed using the developed Simulink model. The simulation has been conducted with and without a fleet of electric cars that use the proposed control strategy.

\subsection{Western part of the UCTE-grid}

The fleet in the part of the network consists of $1,300,000$ electric cars actively charging their batteries at the maximum rating of $95 \%$. Already 100,000 vehicles are capable of influencing the grid frequency, but are not able to balance the power during such a heavy disturbance as in 2006. The number of vehicles in standby mode is not relevant in this case, since they could only increase power consumption. The rated power of the connection is chosen to be $11 \mathrm{~kW}$, like it is usual for regular three phase connections in Germany.

The result shown in Fig. 4 confirms that the frequency stability can be improved. Without the reaction of electric cars, the frequency drops quickly down to $49 \mathrm{~Hz}$, which triggers load shedding. About $15 \mathrm{GW}$ loads are shed, which stops the frequency from falling even lower and creates a small power surplus. This, in combination with the primary reserve, leads to a slowly rising frequency.

The red dashed curve shows the simulation with electric vehicles. Those react quickly to the frequency drop due to the differential part of the control. Therefore the frequency decreases much slower, and stays above $49 \mathrm{~Hz}$. Only about $3 \mathrm{GW}$ of loads are shed in this simulation, of which half are pump storage power plants. After $24 \mathrm{~s}$ of the disturbance, the frequency is lower than it is without the electric cars. This seems contradictory, but it is purely based on the fact, that fewer loads were shed.

During the first minute after fault, the simulation without virtual synchronous machines is close to the real frequency behaviour during the fault in Europe in 2006. The system behaviour after the first minute cannot be reproduced with the developed model, due to its limitation on primary reserve and system inertia.

If the power rating is chosen higher, a smaller number of vehicles will lead to similar results. If the vehicles are connected with bidirectional connections, enabling them to feed power into the grid, also inactive vehicles could support the grid, and actively changing vehicles could support the grid more effectively. Similar results can be achieved with a smaller number of vehicles with bidirectional connection.

\subsection{North-eastern part of the UCTE-grid}

In Fig. 5 the simulation results for the north-eastern part of the grid are plotted. In this part of the network, a large power surplus endangered the system after splitting off from the rest of Europe. The solid black curve shows how strongly the frequency oscillates right after the grid is split. If 500,000 inactive electric cars placed within the north-eastern region react to frequency changes, activate themselves, and consume power to absorb the surplus until the primary reserve is activated, the oscillations can be avoided.

About $1 \mathrm{~min}$ after the disturbance, the frequencies are almost identical, with and without electric vehicles. This indicates, that the contribution of the converters is only of short duration, basically bridging the time gap between disturbance and primary reserve activation.

\section{Summary}

A new control method for power converters in electrical grids is developed, which is based on the principle of a virtual synchronous machine. The developed control method is suitable for converter loads, storage and generation and can significantly improve frequency stability. Since a lot of power converters like battery charging devices use only a small part of their technical potential, the unused capacities can be utilized to influence the power balance of the entire grid. The additional control power can support frequency stability even before the primary reserve is activated.

Converter systems without flexibility, like the drives of an industrial robot, cannot take part in grid stabilization, since their active power flows are already determined at any moment by their primary task.

The chosen control parameters like frequency dependency and virtual angular momentum are much larger than the parameters of a real synchronous machine. This positively influences the frequency stability of the power system.

In case of severe frequency deviations, priority is given to the frequency support functionality of the converter. While at $50.0 \mathrm{~Hz}$ the control only fulfils the primary task of the converter, it changes more and more in direction of full grid support, the more and faster the frequency changes. This can help in keeping the power balance in case of large power shortages that exceed the capability of the primary reserves. The frequency can be stabilized until the secondary control is activated and therefore load shedding can be avoided, which significantly improves the overall security of supply.

The control can be applied to converter system representing loads, sources and even bidirectional storage units, which can reverse power flow to support the grid under severe disturbance. 
Fig. 4 Simulated and measured grid frequency in western grid part 2006 [2]
Fig. 5 The simulated grid frequency in the north eastern grid part 2006
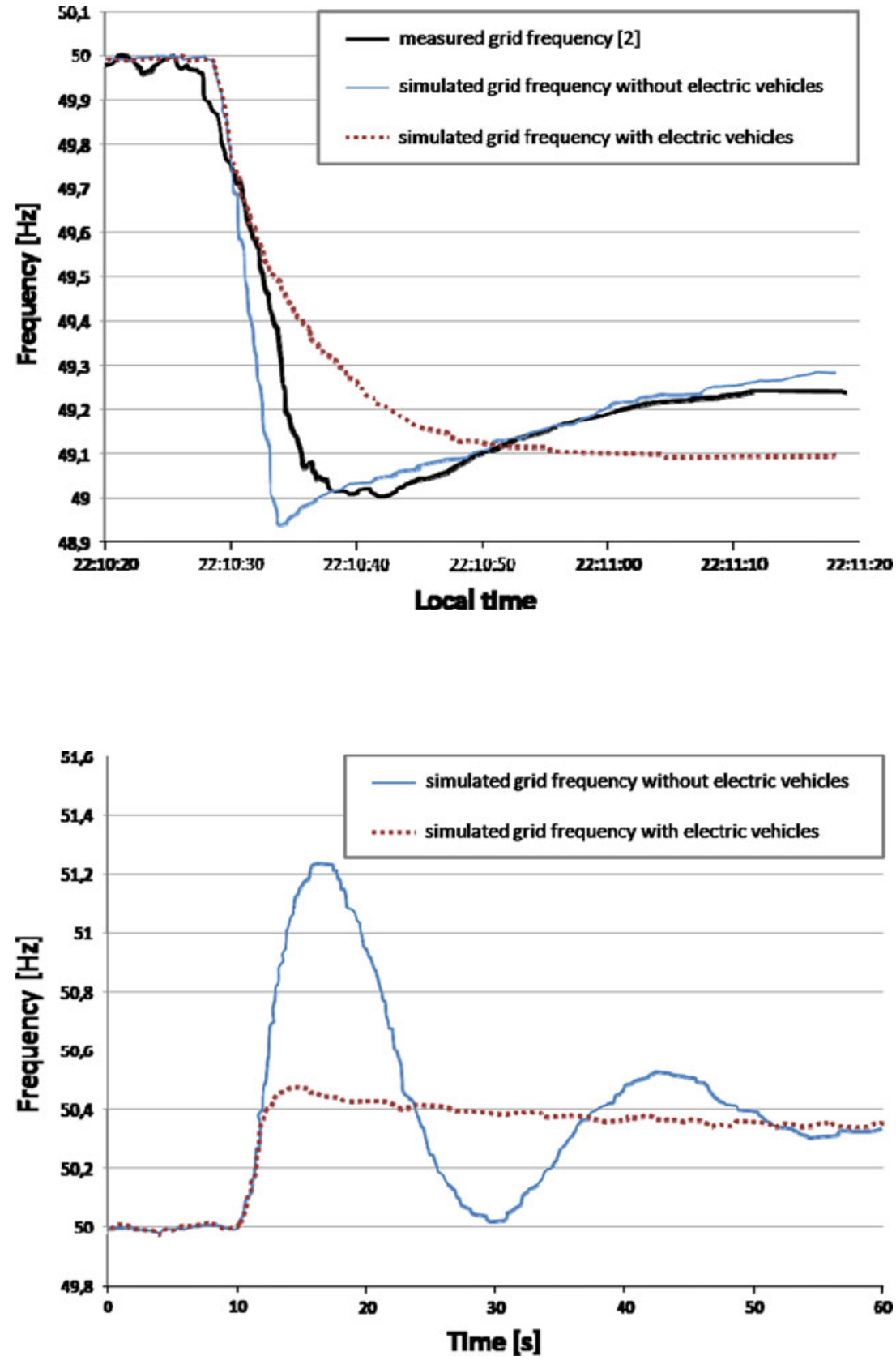

Not only active power converters are taken into account by this control method. Electric vehicles with a fully charged battery are inactive, but can still engage in frequency response under emergency conditions if necessary.

An advantage of this control algorithm is its autonomous behaviour. No communication between network operator and vehicle is necessary for the basic grid supporting functions.

The differential part of the developed control algorithm is also an important addition to classical droop-based controllers. Droop control only reacts, if the frequency already has changed, while the differential control reacts earlier and tries to prevent a frequency change.

The simulation results ${ }^{1}$ indicate that a small percentage of vehicles equipped with the developed control strategy can significantly influence the grid frequency in Europe in a positive way.

\footnotetext{
1 The control method was developed and the simulation was conducted as part of the diploma thesis by T. K. Vrana, "Analysis and Definition of Technical Specifications of Dispersed Inverter-Based Energy Conversion Units in Distribution Grids" (2008).
} 


\section{Appendix}

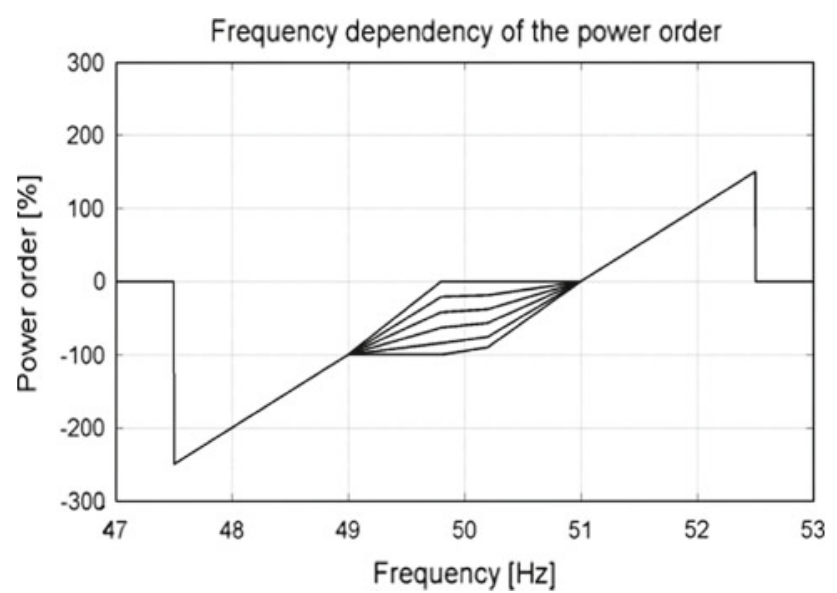

Fig. 6 The frequency dependency of the power order for generation units

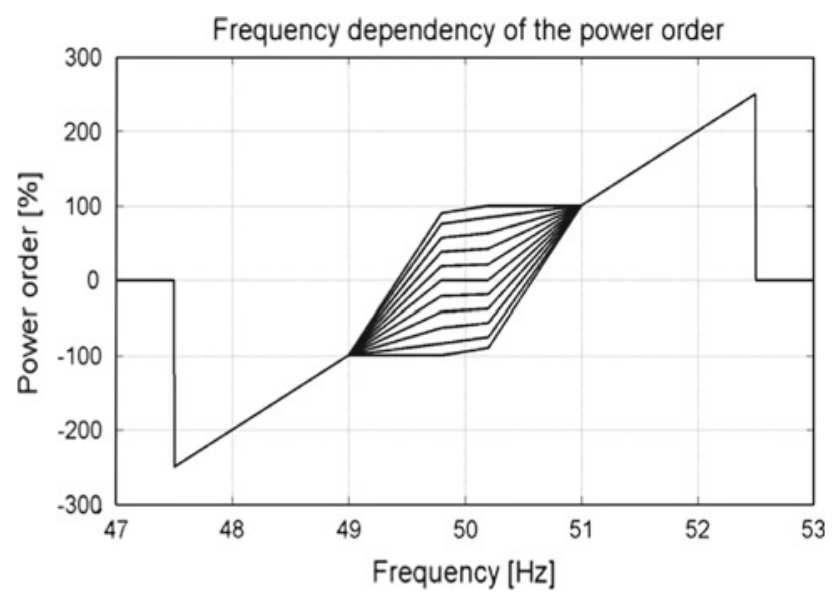

Fig. 7 The frequency dependency of the power order for bidirectional converter systems

Open Access This article is distributed under the terms of the Creative Commons Attribution Noncommercial License which permits any noncommercial use, distribution, and reproduction in any medium, provided the original author(s) and source are credited.

\section{References}

1. Vandenberghe F et al (2004) FINAL REPORT of the Investigation Committee on the 28 September 2003 Blackout in Italy, UCTE

2. Maas GA et al (2007) Final Report-System Disturbance on 4 November 2006, UCTE

3. Strauss P, Meyer T (2005) Impact of network disturbances on inverter based DG: solutions for increased reliability, DISPOWER Project Highlight No. 29

4. Hughes FM, Anaya-Lara O, Jenkins N, Strbac G (2005) Control of DFIG-based wind generation for power network support. IEEE Trans Power Syst 20(4):1958-1966

5. Lalor G, Mullane A, O'Malley M (2005) Frequency control and wind turbine technologies. IEEE Trans Power Syst 20(4):19051913

6. Dynamic Demand (2005) A dynamically-controlled refrigerator, London

7. Engler A (2005) Applicability of droops in low voltage grids. DER J 1 Jan 2005

8. de Brabandere K, Bolsens B, van den Keybus J, Woyte A, Driesen J, Belmans R (2007) A voltage and frequency droop control method for parallel inverters. IEEE Trans Power Electr 22(4):1107-1115 July 2007

9. Hamsic N, Schmelter A, Mohd A, Ortjohann E, Schultze E, Tuckey A, Zimmermann J (2006) Stabilising the grid voltage and frequency in isolated power systems using a flywheel energy storage system. Great Wall World Renewable Energy Forum, Beijing, 23-27 October 2006

10. Kramer B, Chakraborty S, Kroposki B (2008) A review of plug-in vehicles and vehicle-to-grid capability, IEEE

11. Lopes JA, Polenz SA, Moreira CL, Cherkaoui R (2010) Identification of control and management strategies for LV unbalanced microgrids with plugged-in electric vehicles. Electr Power Syst Res

12. Beck HP, Hesse R (2007) Virtual synchronous machine, 9th international conference. Electrical power quality and utilisation, Barcelona, 9-11 October 2007

13. Horbaty R, Rigassi R (2007) Integration von Plug-in-Hybrid Cars zur Förderung intelligenter Verteilnetzstrukturen, ENCO-EnergieConsulting AG

14. Kempton W, Tomic J (2005) Vehicle-to-grid power implementation: from stabilizing the grid to supporting large-scale renewable energy. Science Direct

15. Guille C, Gross G (2008) Design of a conceptual framework for the V2G implementation. IEEE Energy 2030 Atlanta, 17-18 November 2008

16. Haubrich H-J (2006) Power systems. IAEW, RWTH-Aachen

17. UCTE (2004-2009) UCTE operation handbook, Brussels

18. Holst A, Prillwitz F, Weber H, Schmidt C (2003) Netzregelverhalten von Windkraftanlagen, VDE/VDI: 6. GMA/ETG-Fachtagung, 21-22 Mai, München, Heft 25

19. de Haan SWH, Visscher K (2008) Virtual synchronous machines for frequency stabilisation in future grids with a significant share of decentralized generation. CIRED Seminar 23-24 June, Frankfurt 